\title{
VIRION-LIPOSOME INTERACTIONS IDENTIFY A CHOLESTEROL-INDEPENDENT CORONAVIRUS ENTRY STAGE
}

\author{
Joseph A. Boscarino, Jeffrey M. Goletz, and Thomas M. Gallagher*
}

\section{INTRODUCTION}

Entry of enveloped viruses depends on several cellular components, including protein or carbohydrate receptors and oftentimes co-receptors that both bind viruses to cells and catalyze the initial stages of viral surface protein refolding. ${ }^{1}$ Endocytosis is a common prerequisite to successful entry; both the acidic $\mathrm{pH}$ and the proteases of the endosome can create further structural changes in the viral proteins mediating cell receptor binding and virus-cell membrane fusion. ${ }^{2}$ Finally, an appropriate lipid environment, often abundant in sterols, is also frequently necessary to achieve facile fusion of viral and cellular membranes. ${ }^{3}$ In numerous seminal investigations, each of these steps has been dissected by blocking virus entry with mutant transgenes or with drugs that alter receptors or endosome or lipid environments. Although these are powerful approaches, the findings can be complicated when the transgenes or drugs create untoward pleiotropic changes in cellular functions. A complementary reductionist approach involves in vitro virus entry in which enveloped viruses are bound to and then fused into synthetic liposomes. ${ }^{4}$ In these test-tube reactions, receptors, $\mathrm{pH}$, proteases and liposome bilayer compositions can be precisely defined and freely altered in ways not achievable in living cells. Such systems are useful adjuncts to understanding the biochemistry of enveloped virus entry.

In vitro virus-liposome binding assays have been recently developed for the murine coronaviruses. ${ }^{5,6}$ In these studies, purified MHV particles acquired hydrophobic character by incubation with soluble MHV receptors or by exposures to elevated $\mathrm{pH}$, thus causing a small proportion of the virus population to associate with liposomes. We aimed to advance these studies by creating liposomes that more closely reflect authentic MHVsusceptible cells. To this end, we created synthetic liposomes containing nickelnitriloacetic acid (NiNTA) adducts on a fraction of lipid head groups. Soluble MHV receptors containing engineered polyhistidine tags could then be attached to the liposomes, thereby creating artificial targets for virus binding. These liposomes with

*Loyola University Medical Center, Maywood, Illinois 60153. 
attached receptors have been useful in identifying the requirements for irreversible association of MHV to target membranes during entry.

\section{RESULTS}

We obtained lipids from Avanti Polar Lipids, Inc., including the novel synthetic product DOGS-NTA-Ni, which contains a chelated $\mathrm{Ni}^{+2}$-NTA head group that can noncovalently complex with polyhistidine tags. Lipids in various formulations [typically 69:30:1 mole ratio phosphatidylcholine (PC), cholesterol (chol), DOGS-NiNTA] were suspended from a dried state into HEPES-buffered saline and then extruded through polycarbonate filters to create 100 -nm-diameter liposomes. These liposomes were then mixed with baculovirus-expressed soluble MHV receptors containing C-terminal 6xhistidine tags. ${ }^{7}$ These soluble receptors are designated soluble Carcino-EmbryonicAntigen, or sCEA6his. To remove unbound receptors, we adjusted the mixtures to contain $50 \% \mathrm{w} / \mathrm{v}$ sucrose, then overlaid stepwise with $40 \%-30 \%-10 \% \mathrm{w} / \mathrm{v}$ sucrose solutions and floated the liposomes to the $10-30 \%$ sucrose interface by ultracentrifugation. The liposome:sCEA6his complexes were collected and stored at $4^{\circ} \mathrm{C}$. Estimates of the sCEA-6xhis concentrations by titration and immunoblotting indicated that our typical preparations had densities of $\sim 50$ sCEA per 100-nm liposome.

Metabolically-radiolabeled $\left[{ }^{35} \mathrm{~S}\right] \mathrm{MHV}$ particles were purified by equilibrium density gradient sedimentation. Typically, we incubated $\sim 50,000 \mathrm{cpm}$ of $\left[{ }^{35} \mathrm{~S}\right] \mathrm{MHV}\left(10^{5} \mathrm{pfu}\right)$ for $1 \mathrm{~h}$ at $4^{\circ} \mathrm{C}$ with $10 \mathrm{mM}$ phospholipid liposomes, in a volume of $0.2-\mathrm{ml}$ of HEPESbuffered saline. Mixtures were then brought to $50 \%$ sucrose and subjected to a second round of ultracentrifugation to float the liposomes. By identifying the $\left[{ }^{35} \mathrm{~S}\right]$-containing gradient fractions, we determined that MHV binding to liposomes was absolutely dependent on NiNTA lipids and on sCEA6his (Fig. 1). Notably, a control sCEAFc lacking the $6 x$ his tag bound to the $\left[{ }^{35} \mathrm{~S}\right]$ virions, but failed to link virions to liposomes (Fig. 1), even after incubation at $37^{\circ} \mathrm{C}$.

To determine whether the connections between $\left[{ }^{35} \mathrm{~S}\right] \mathrm{MHV}$ and liposomes were reversible, we exploited the common knowledge that noncovalent NiNTA:6his linkages are disrupted by EDTA or imidazole. To this end, we harvested $\left[{ }^{35} \mathrm{~S}\right] \mathrm{MHV}$-liposome complexes from gradient fractions and added EDTA (10 mM final concentration) for 30 $\min$ at $4^{\circ} \mathrm{C}$. Reflotation in fresh sucrose gradients revealed that the EDTA exposures separated the virions, leaving the $\left[{ }^{35} \mathrm{~S}\right]$ near the bottom of the ultracentrifuge tubes (Fig. 2). However, MHV-liposome complexes incubated for $30 \mathrm{~min}$ at $37^{\circ} \mathrm{C}$ were insensitive to dissociation by EDTA (Fig. 2). This discovery allowed us to conclude that physiologic temperature is required to establish EDTA-resistant linkages between virus and its target lipid bilayer.

MHV entry requires cholesterol in target lipid bilayers. ${ }^{8}$ To determine whether the irreversible virus-liposome linkages required cholesterol, we prepared liposomes lacking and containing $30 \mathrm{~mol} \%$ cholesterol. These two liposome formulations were indistinguishable in their irreversible, $37^{\circ} \mathrm{C}$ temperature-dependent capture of $\left[{ }^{35} \mathrm{~S}\right] \mathrm{MHV}$ particles (Fig. 2). 


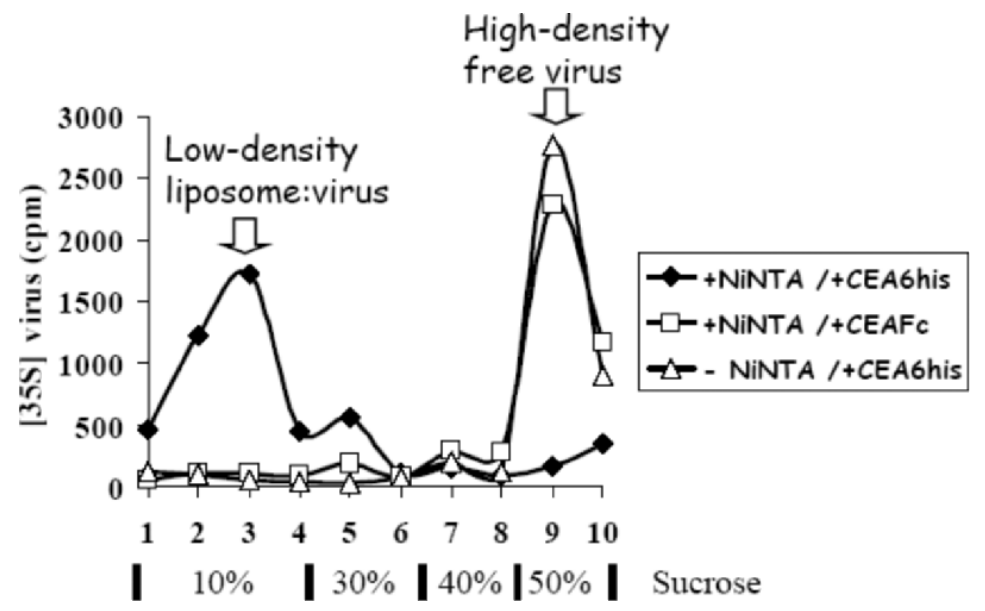

Figure 1. Virus-liposome interactions require both sCEA6his and NiNTA lipids. Liposomes with or without incorporated NiNTA lipids were incubated with either sCEA6his or sCEAFc, then with purified $\left.{ }^{35} \mathrm{~S}\right] \mathrm{MHV}$ strain $\mathrm{A} 59$ for $1 \mathrm{~h}$ at $4^{\circ} \mathrm{C}$ before floating liposomes in sucrose gradients. The abundance of $\left[{ }^{35} \mathrm{~S}\right]$ in $1 / 10$ of each of the gradient fractions were determined by scintillation counting.

\section{DISCUSSION}

Coronavirus particles are distinguished by their prominent spike protein trimers. These glycoproteins bind cell receptors and mediate virus-cell membrane fusions. The fusion reaction pathway is of the "class I" type", which involves a temperature-dependent refolding into helical bundles. In a productive process, this refolding is preceded by

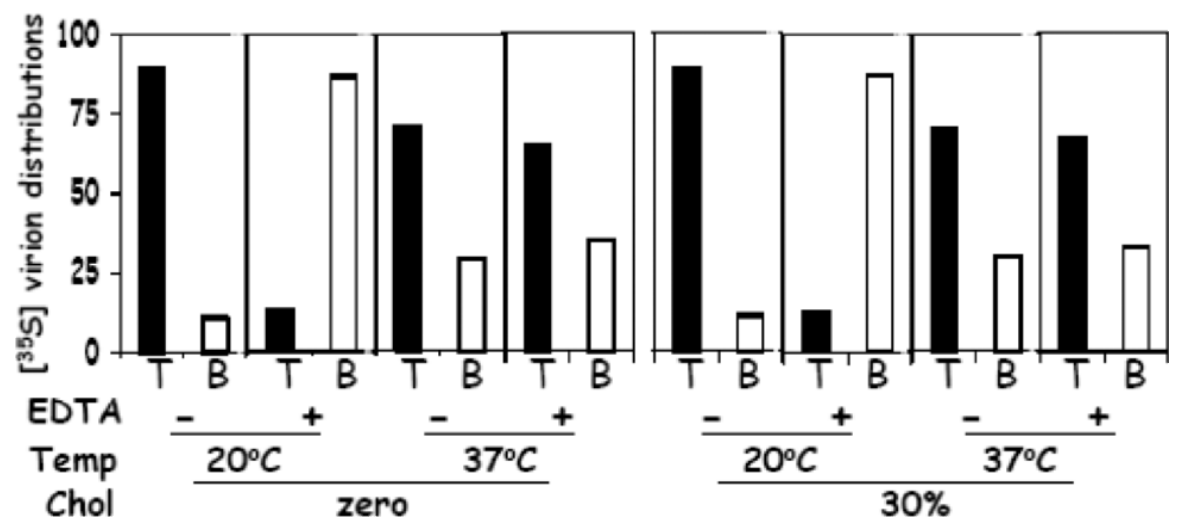

Figure 2. Stability of virus-liposome complexes against dissociation by EDTA. $\left[{ }^{35} \mathrm{~S}\right]$ MHV-liposome complexes, purified by floatation in sucrose gradients, were held at $20^{\circ} \mathrm{C}$ or $37^{\circ} \mathrm{C}$ prior to EDTA exposure. Samples were then subjected to a second round of floatation, and the proportion of $\left.{ }^{35} \mathrm{~S}\right]$ in the top (T) and bottom (B) of each gradient were determined by scintillation counting. The $\left[{ }^{35} \mathrm{~S}\right]$ in $\mathrm{T}$ and $\mathrm{B}$ represent virusliposome complexes and free virus, respectively. EDTA released viruses from liposomes at $20^{\circ} \mathrm{C}$, but $37^{\circ} \mathrm{C}$ temperatures created EDTA-stable virus-liposome complexes. 
insertion of hydrophobic spike peptides, so-called fusion peptides, into target membranes. We are currently hypothesizing that the stabilized association of MHV with synthetic liposomes results from the insertion of their fusion peptides into the liposome membranes. If this hypothesis is borne out, then we can suggest that the intercalation of fusion peptides is strongly temperature-dependent but does not require cholesterol in the target membranes.

In assessing whether bona-fide fusion of virus and liposome membranes occurs, our principal strategy has been to monitor fluorescence changes as pyrene lipid probes redistribute from limiting membranes into the larger area of fused vesicles. ${ }^{4}$ Despite numerous attempts, we have not yet documented MHV:liposome coalescence by these methods. It is entirely possible that components required to complete the MHV membrane fusion process are missing from our in vitro assays. Fusion may require exposure to acids or proteases, may require proteinaceous co-factors in addition to the principal CEA receptors, and likely also requires specific sterol-containing lipid environments. We are continuing our investigations to identify the conditions that may allow completion of the spike-mediated class I fusion pathway.

\section{ACKNOWLEDGMENTS}

We thank Dr. Fumihiro Taguchi (National Institute of Infectious Diseases, Tokyo, Japan) for providing baculovirus recombinants encoding sCEA6xhis. This work was funded by PHS grant NIH AI60030.

\section{REFERENCES}

1. Chen, B., Vogan, E. M., Gong, H., Skehel, J. J., Wiley, D. C., and Harrison, S. C., 2005, Structure of an unliganded simian immunodeficiency virus gp120 core, Nature 433:834-841.

2. Simmons, G., Gosalia, D. N., Rennekamp, A. J., Reeves, J. D., Diamond, S. L., and Bates, P., 2005, Inhibitors of cathepsin L prevent severe acute respiratory syndrome coronavirus entry, Proc. Natl. Acad. Sci. USA 102:11876-11881.

3. Rawat, S. S., Viard, M., Gallo, S. A., Rein, A., Blumenthal, R., and Puri, A., 2003, Modulation of entry of enveloped viruses by cholesterol and sphingolipids, Mol. Membr. Biol. 20:243-254.

4. Smit, J. M., Waarts, B. L., Bittman, R., and Wilschut, J., 2003, Liposomes as target membranes in the study of virus receptor interaction and membrane fusion, Methods Enzymol. 372:374-392.

5. Tsai, J. C., Zelus, B. D., Holmes, K. V., and Weiss, S. R., 2003, The N-terminal domain of the murine coronavirus spike glycoprotein determines the CEACAM1 receptor specificity of the virus strain, J. Virol. 77:841-850.

6. Zelus, B. D., Schickli, J. H., Blau, D. M., Weiss, S. R., and Holmes, K. V., 2003, Conformational changes in the spike glycoprotein of murine coronavirus are induced at 37 degrees $\mathrm{C}$ either by soluble murine CEACAM1 receptors or by $\mathrm{pH} 8, J$. Virol. 77:830-840.

7. Taguchi, F., and Matsuyama, S., 2002, Soluble receptor potentiates receptor-independent infection by murine coronavirus, J. Virol. 76:950-958.

8. Thorp, E. B., and Gallagher, T. M., 2004, Requirements for CEACAMs and cholesterol during murine coronavirus cell entry, J. Virol. 78:2682-2692.

9. Bosch, B. J., van der Zee, R., deHaan, C. A., and Rottier, P. J., 2003, The coronavirus spike protein is a class I virus fusion protein: structural and functional characterization of the fusion core complex, J. Virol. 77:8801-8811.

10. Sainz, B., Rausch, J. M., Gallaher, W. R., Garry, R. F., and Wimley, W. C., 2005, Identification and characterization of the putative fusion peptide of the severe acute respiratory syndrome-associated coronavirus spike protein, J. Virol. 79:7195-7206. 